\title{
Safety reporting study of nonsteroidal anti-inflammatory drugs in a tertiary care teaching hospital, SIMS, Uttar Pradesh
}

\author{
Saborni Dey ${ }^{1 *}$, Harsh Kumar², Anand Kumar Shukla ${ }^{1}$
}

${ }^{1}$ Department of Pharmacology, Saraswathi Institute of Medical Sciences, Hapur, Uttar Pradesh, India

${ }^{2}$ Department of Orthopedics, Saraswathi Institute of Medical Sciences, Hapur, Uttar Pradesh, India

Received: 28 July 2020

Accepted: 31 August 2020

\author{
*Correspondence: \\ Dr. Saborni Dey, \\ Email: sabornidey7@gmail.com
}

Copyright: (C) the author(s), publisher and licensee Medip Academy. This is an open-access article distributed under the terms of the Creative Commons Attribution Non-Commercial License, which permits unrestricted non-commercial

\begin{abstract}
Background: The nonsteroidal anti-inflammatory drugs (NSAIDs) are among the most frequently used drugs to treat pain and inflammation. Although NSAIDs are having enormous clinical use, but are not devoid of adverse drug reactions (ADRs) as peptic ulcer, gastritis, renal, neurological reactions etc. So, this pilot study is intended to assess the incidence and pattern of ADRs of the NSAIDs in a tertiary care teaching hospital.

Methods: Total 600 Orthopaedic out-patients of SIMS, Hapur were enrolled in the study to observe the risk of ADRs due to NSAIDs. All the ADRs were further analysed in relation to age, sex, types of drug and its pattern etc. The causality was analysed by using Naranjo's Algorithm and severity was analysed by using the Hartwing and Siegel scale.

Results: Out of the 600 patients with NSAID therapy, 35 patients $(5.83 \%)$ experienced total 10 types of ADRs. The adverse drug reactions observed by the patients were gastric symptoms, headache, urticaria, oedema etc. The most frequently observed ADR was gastritis. With all the prescribed drugs Tab Diclofenac sodium accounted for $57.14 \%$ and Paracetamol for $11.42 \%$ of all the ADRs. According to Naranjo's Algorithm $62.87 \%$ ADRs were possible' and $37.14 \%$ were of probable type and ADRs were mostly mild in severity.

Conclusion: In this study, incidence of adverse reactions to nonsteroidal anti-inflammatory drugs was 5.83 and the most common implicated drug for the ADRs were Diclofenac sodium. Most of the adverse effects were mild and tolerable.
\end{abstract}

Keywords: Adverse drug reactions, Nonsteroidal anti-inflammatory drugs, Pharmacovigilance

\section{INTRODUCTION}

World Health Organisation defined an ADR as a response which is noxious and unintended, which occurs at doses normally used in humans for prophylaxis, diagnosis or therapy of disease or for the modification of physiological function. ${ }^{1}$ Pain is a qualitative, subjective feeling and management of pain is also very important in patients. Accurate diagnosis of disease with appropriate treatment of pain is pivotal for the well-being of the patients suffering from acute and chronic pain.

Analgesics have been identified as one of the most commonly prescribed drugs for pain management and provide highest quality of life possible for patients with their disease conditions. It is an inter-disciplinary approach for easing the suffering and improving health of those living with pain. NSAIDs are among most widely used drugs with analgesic, antipyretic and antiinflammatory effect. NSAIDs constitute the largest single group of drugs used world-wide, constituting more than $20 \%$ of all drug prescriptions. ${ }^{2}$ Other than their different therapeutic uses NSAIDs are also one of the common causes of adverse drug reactions reported to drug regulatory organizations as well as in many clinical and epidemiological studies. The use of NSAIDs is most frequent predisposing factor for peptic ulcer and approximately $10-20 \%$ patients who receive prolonged 
NSAID therapy develop asymptomatic peptic ulceration and ulcer related complications (bleeding, perforation, malignancy) that develops in $1-2 \%$ persons per year. ${ }^{3}$

The identification, assessment and prevention of ADR is an important mandatory process of hospitals. Pharmacovigilance, though an integral part of drug therapy but still it is not widely executed in Indian hospitals. So, we conduct the study to analyse the ADRs which are related to NSAIDs, so that these can be prevented further. NSAIDs are like a two-edged sword as we have no better option than these drugs and also have to deal with its adverse reactions. Therefore, the present study was carried to monitor and evaluate the various adverse events occurring due to NSAIDs in a multispeciality teaching hospital in India.

\section{METHODS}

The prospective, observational study was executed in the department of Orthopaedics with association of the department of Pharmacology, SIMS Medical College, Hapur, UP. The study was regulated for 8 months of duration from July 2018 to March 2019 after obtaining Institutional Ethical clearance. All the newly registered patients of either sex, of the age groups between 18 to 70 years, who were on NSAID therapy for various painful, inflammatory condition were included for the study. Patients with history of liver or kidney damage, cardiovascular disease, acid peptic disease, pregnant and lactating females were all excluded from the study.

A total 600 patients were enrolled after getting their informed and written consent as per the inclusion and exclusion criteria. Demographic details, diagnosis, medical history, details of their examination and concomitant medications were recorded with proper proforma. Detailed history of ADR (drug name, dose, frequency, date of onset, pattern etc) was recorded in separate proforma. A structured questionnaire was used to record the adverse effect. The causality was assessed by using Naranjo's Algorithm, which is one of the most widely used methods for evaluating adverse reactions. ${ }^{4}$ It consists of 10 questions and each question was given a score. The total score was recorded for each patient and graded as definite, probable, possible and doubtful. The severity of the ADRs were grouped as mild, moderate or severe (assessed by using the Hartwing and Siegel scale) ${ }^{5}$

Review was done to identify any new symptoms that were not present prior to the start of the drug therapy. Also worsening of existing symptoms and any change in the laboratory values compared with the baseline values were evaluated to detect an ADR. The out-patients were monitored during their subsequent visits to the out-patient department over a period of 1 month.

Data was collected and analysed by using the Chi-square with two tailed test. A $\mathrm{p}<0.05 \%$ was considered as significant. Numerical values were expressed in percentage and tabulated.

\section{RESULTS}

Among the sample size of 600 patients who were treated with NSAIDs 35 patients had developed ADRs $(n=35)$. Out of 600 patients $390(65 \%)$ patients were male and $210(35 \%)$ were female. The Male: Female ratio of the study group was 1.8:1 and the demographic details of the patients are observed and tabulated (Table 1).

Table 1: The demographic features of the patients.

\begin{tabular}{|llll|}
\hline $\begin{array}{l}\text { Age groups } \\
\text { (years) }\end{array}$ & Male (\%) & Female (\%) & Total \\
\hline $\mathbf{1 8 - 6 5}$ & 366 & 198 & 564 \\
\hline $\mathbf{6 5 - 7 0}$ & 24 & 12 & 36 \\
\hline Total & $390(65)$ & $210(35)$ & 600 \\
\hline
\end{tabular}

Average number of ADR per patient was 0.29. Out of 35 patients who suffered of ADR $22(62.86 \%)$ patients were male and $13(37.14 \%)$ patients were female. With respect of age groups, $29(82.86 \%)$ ADRs were reported in the age group of 18-65 years and $6(17.14 \%)$ were reported in the age group of 65-70 years listed in Table 2 . In this study age and gender had no statistical significance ( $p>0.05$ ) with respect to the occurrence of adverse drug reaction due to NSAIDS prescribed (Table 2).

Table 2: Age of the patients and ADR.

\begin{tabular}{|llll|}
$\begin{array}{l}\text { Age groups } \\
\text { (years) }\end{array}$ & $\begin{array}{l}\text { Patients } \\
\text { with ADR } \\
\text { n }(\%)\end{array}$ & $\begin{array}{l}\text { Patients } \\
\text { without ADR } \\
\text { n }(\%)\end{array}$ & Total \\
\hline $\mathbf{1 8 - 6 5}$ & 29 & 535 & 564 \\
\hline $\mathbf{6 5 - 7 0}$ & 6 & 30 & 36 \\
\hline Total & $35(5.83)$ & $565(94.16)$ & 600 \\
\hline
\end{tabular}

Chi-square test $x^{2}=3.06$, Degree of freedom (1) $p>0.05$.

During the study it was observed that Diclofenac 390 $(65 \%)$ was the most commonly prescribed drug, followed by Paracetamol 72 (12\%), Nimesulide 60 (10\%), Ibuprofen 36 (6\%), Piroxicam 30 (5\%) and Etoricoxib 12 $(2 \%)$. As the number of prescriptions of Diclofenac was more, the percentage of ADRs with this drug was also more. Out of 35 ADRs, $20(57.14 \%)$ were due to Diclofenac, 4 (11.43\%) due to Paracetamol, 4 (11.43\%) to Nimesulide, $4(11.43 \%)$ by Ibuprofen, $2(5.71 \%)$ due to Piroxicam and $1(2.86 \%)$ were due to Etoricoxib. (Table 3).

Out of the 40 suspected ADRs identified, 5 ADRs could not be evaluated for casual relationship due to nonavailability of the data. The causality assessment unveiled that 22 ADRs $(62.867 \%)$ belonged to the possible category, whereas $13(37.142 \%)$ were probable reactions according to the Naranjo's Algorithm. 
In this study the incidence rate of the ADRs was around $5.83 \%$. Among the 35 patients who had developed ADRs, a total 10 kinds of ADRs were observed. The reactions that affected the study subjects were gastritis, nausea, vomiting, abdominal Pain, diarrhoea, urticaria, pruritus, headache, rash, ankle oedema and dizziness. Majority of ADRs $31(88.57 \%)$ were mild in their severity and that 4 $(11.43 \%)$ ADRs were moderate in nature. All the ADRs were treated symptomatically by using standard treatment protocols (Table 4).

Table 3: Drug utilization and ADRs.

\begin{tabular}{|lll|}
\hline Name of drugs & $\begin{array}{l}\text { Number of } \\
\text { patients }\end{array}$ & $\begin{array}{l}\text { Number of } \\
\text { ADRs }\end{array}$ \\
\hline Diclofenac sodium & 390 & 20 \\
\hline Paracetamol & 72 & 4 \\
\hline Nimesulide & 60 & 4 \\
\hline Ibuprofen & 36 & 4 \\
\hline Piroxicam & 30 & 2 \\
\hline Etoricoxib & 12 & 1 \\
\hline Total & 600 & 35 \\
\hline
\end{tabular}

Table 4: ADRs detected and implicated drugs.

\begin{tabular}{|l|ll|}
\hline ADRs & $\begin{array}{l}\text { Total } \\
\text { no. of } \\
\text { patients }\end{array}$ & $\begin{array}{l}\text { Drugs causing the adverse } \\
\text { effect (number of patients) }\end{array}$ \\
\hline Gastritis & 9 & $\begin{array}{l}\text { Diclofenac-4, Paracetamol-2, } \\
\text { Nimesulide-1, Ibuprofen-2 }\end{array}$ \\
\hline Nausea & 6 & $\begin{array}{l}\text { Diclofenac-4, Nimesulide-1, } \\
\text { Ibuprofen-1 }\end{array}$ \\
\hline Vomiting & 2 & Nimesulide-2 \\
\hline $\begin{array}{l}\text { Abdominal } \\
\text { pain }\end{array}$ & 5 & Diclofenac-5 \\
\hline Diarrhoea & 3 & Diclofenac-2, Ibuprofen-1 \\
\hline $\begin{array}{l}\text { Urticaria } \\
\text { and } \\
\text { pruritus }\end{array}$ & 2 & Diclofenac-2 \\
\hline Headache & 3 & Diclofenac-2, Paracetamol-1 \\
\hline Rash & 2 & Diclofenac-1, Piroxicam-1 \\
\hline $\begin{array}{l}\text { Ankle } \\
\text { oedema }\end{array}$ & 1 & Piroxicam-1 \\
\hline Dizziness & 2 & Etoricoxib-1, Ibuprofen-1 \\
\hline
\end{tabular}

\section{DISCUSSION}

This potential study findings underline the incidence and pattern of ADR of analgesics like NSAIDs in Orthopaedic setting in the Indian scenario. The prevalence rate of ADRs to NSAIDs in our study was $5.83 \%$. A study conducted in Mumbai revealed the incidence rate of various kinds of ADRs of NSAIDs ranging between $28 \%$ to $33 \%$, higher than our findings. ${ }^{6}$ In another recent study on adverse drug reactions of NSAIDs in orthopaedic patients of Delhi reported that the prevalence rate of ADR was 26\%.7 But decreased incidence rate of $5.5 \%$ was found as seen in a study by
Venkatachalam that was relatively closer with our study findings. ${ }^{8}$

Rational usage of NSAIDs, their proper selection and selection of proper treatment guideline protocols are important for decreased number of ADRs in the present study. During the study, majority of the ADRs were reported by active surveillance and it was observed that spontaneous reporting rate was also increased by clinical physicians.

In this study, 36 patients were in the age between $65-70$ years and among them $6(17.14 \%)$ patients had developed ADR, while $29(82.86 \%)$ ADRs reported in the age group of 18-65 years. The analysis of association between the incidence of ADRs and age revealed relationship between increased ADRs in increased age groups. But in our study, age had no statistical significance with respect to the occurrence of ADRs caused by NSAIDs prescribed. Some studies showed the highest percentage of ADRs were present in the older age groups $<65$ years. ${ }^{9,10}$ Our findings differ from that of Egger et al and other studies, where the elderly were more commonly affected. ${ }^{11}$

In this study, out of all the ADRs, 22 (62.86\%) occurred in males and $13(34.14 \%)$ developed in females. According to our study gender had no statistical significance with respect to the occurrence of ADR caused by NSAIDs. Study showed that ADRs were most commonly observed in women $(66.30 \%)$ than in men $(33.80 \%)$. The relationship between the incidence of ADRs and gender was also confirmed by BalinskaMiskiewicz et al, in the epidemiological evaluation of the incidence of risk factors for drugs. ${ }^{12}$ In another study also showed that the number of female patients suffering from ADRs due to NSAIDs were more than male counterpart. ${ }^{13}$

Multiple studies had been done to comprehend the possible risk factors of NSAIDs that increase ADRs like G.I toxicity. Results from different studies help us to speculate that if we collect more information, more risk factors will be discovered. In this current study, we can substantiate specific risk factors to predict the overall occurrences of ADRs induced by NSAIDs. ADRs associated with NSAIDs primarily manifest in gastrointestinal, cardiovascular and renal sites. Diclofenac sodium was the most frequently prescribed drug followed by Paracetamol. Other prescribed NSAIDs were Nimesulide, Ibuprofen, Piroxicam and Etoricoxib.

Out of 35 ADRs, $20(57.14 \%)$ were due to Diclofenac and $4(11.43 \%)$ were due to Paracetamol. Due to Nimesulide $4(11.43 \%)$, Ibuprofen $4(11.43 \%)$, Piroxicam $2(5.71 \%)$ and Etoricoxib $1(2.86 \%)$ ADRs developed. The percentage of ADRs due to Diclofenac was in the line with two other studies in Gujarat and Chennai. ${ }^{7,8}$

Since the number of patients who received Diclofenac was more in comparison to the number that received 
other NSAIDs; the number of ADR was also more with Diclofenac. Again, Diclofenac and Paracetamol are having wide therapeutic window for drug safety and due to this prescribed persistently. Among all the patients who developed ADR due to Diclofenac had symptoms like abdominal pain, gastritis, nausea, diarrhoea, urticaria, pruritus, headache and rash. Some studies have shown that Diclofenac, Ibuprofen and Paracetamol had lesser gastrointestinal side effects in comparison with Piroxicam, Nimesulide, Naproxen. ${ }^{14}$ Another study reported that $20 \%$ of the patients had side-effects due to tablet Diclofenac, but only $2 \%$ discontinued the drug as ADRs were mild in nature. ${ }^{15}$

Other than Diclofenac and Paracetamol, Nimesulide is another drug causing a few ADRs, as it accounts for the same in 4 out of 60 patients. The symptoms of ADR due to Nimesulide were gastritis, nausea, vomiting which suggested no concluding remark. One other study had shown much less incidence rate of ADRs with Nimesulide than our findings. ${ }^{16}$ During one study, on administration of Tab Ibuprofen (5-15\%) of the patients experienced side effect and our study show resemble $(11.43 \%)$ with the findings. ${ }^{8}$ In the study, rest of the NSAIDs as Piroxicam, Etoricoxib were not adequate to draw much conclusion because of the low number of prescriptions.

According to Naranjo's Algorithm, 22 (62.86\%) ADRs were assessed as possible ADRs and 13 (37.14\%) as probable ADRs. Our findings were comparable with the findings of another study of South India whereas $63 \%$ of the ADRs were possibly drug related and $37 \%$ were probably related to the drug. ${ }^{17}$ In this study, most of the reported ADRs were mild $(88.57 \%)$ to moderate $(11.43 \%)$ in their severity according to severity assessment scale and hence did not require withdrawal of the suspected drug when the benefits outweighed the risk. None of the reported ADRs in our study was fatal or severe.

Limitation of the study was, it was undertaken in a single department i.e. orthopaedic patients and the duration was short, the number of patients screened was also less. Further studies may take up with larger study groups involving various departments and study population. So, that pharmacovigilance can be practiced more efficiently.

\section{CONCLUSION}

The present study had documented the incidence of NSAIDs among the Orthopaedic patients in SIMS, Hapur. The incidence rate in Orthopaedic out-patient dept was $5.83 \%$ and the ADRs were non-complicated, mild and easily treatable. It revealed that rational prescribing and drug therapy had brought down the adverse effects to minimal when compared to other studies. Strict adherence to the pharmacovigilance guidelines reduced ADRs and economical burden on patients. It had also attributed to the better prescription practice which was followed by this hospital setup.

Pharmacovigilance is an important tool for the treating physicians to develop protected and effectual medical practice. Identifying the adverse drug events, recording and reporting to the concerned authority is valuable for secure and rational drug therapy. This study has paved the way to carry out further studies on a larger population in the future. Constant vigil in early detection and reporting of ADRs and subsequent management can make therapy with nonsteroidal anti-inflammatory drugs safer and effective.

\section{ACKNOWLEDGEMENTS}

Author would like to thank to the doctors of Orthopaedic Department, SIMS, for their valuable suggestions.

\section{Funding: No funding sources}

Conflict of interest: None declared

Ethical approval: The study was approved by the Institutional Ethics Committee

\section{REFERENCES}

1. The Uppsala Monitoring Centre. Definitions: glossary of terms in pharmacovigilance, http :// www, who-umc. org/ graphics/ 27400. Pdf. Accessed 12 February 2020.

2. Pincus T, Swearingen C, Cunmine P, Callahaw LP. Preference for nonsteroidal anti-inflammatory drugs versus acetaminophen and concomitant use of both types of drugs in patients with osteoarthritis. J Rheumatd. 2000;27:1020-27.

3. Mcquaid KR. Drugs used in the treatment of gastrointestinal diseases. In: Katzung BG, editor. Basic and Clinical Pharmacology. $10^{\text {th }}$ ed. McGraw Hill; 2007:1009-19.

4. Naranjo CA, Busto U, Sellers EM, Sandor P, Ruisl, Roberts EA. A method for estimating the probability of adverse reactions. Clin Pharmacol Ther. 1981;30:239-45.

5. Hartwig SC, Siegel J, Schneider PJ. Preventability and severity assessment in reporting adverse drug reactions. Am J Hosp Pharm. 1992;49:2229-32.

6. Shahani $S$, Nerlekar S. Adverse drug reactions in dermatology and a growing need for pharmacovigilance. J Pharmacovig Drug Saf. 2009;6:35-7.

7. Gor AP, Saksena M. Adverse drug reactions of nonsteroidal anti-inflammatory drugs in orthopaedic patients. J Pharmaco Pharmacother. 2011;2(1):26-9.

8. Venkatachalam S, Bhat R. ADR monitoring of NSAIDs among the in-patients of the orthopedic ward in a tertiary care centre: A prospective observations study. J Clin. Diag Research. 2012;6(1):42-6.

9. Mannesse CK, Derkx FH, Ridder MA, Man in 't Veld AJ, Van der Cammen TJ. Contribution of 
adverse drug reactions to hospital admission of older patients. Age ageing. 2000;29(1):35-9.

10. Hajjar ER, Hanlon JT, Artz MB, Lindblad CI, Pieper $\mathrm{CF}$, Sloane RJ et al. Adverse drug reaction risk factors in older outpatients. AMJ Geriatr. Pharmacother. 2003;1(2):82-9.

11. Egger T, Dormann H, Ahne G, Runge U, Neubert A, Criegee- Rieck M. Identification of adverse drug reactions in geriatric in-patients by using a computerized drug database. J drugs aging. 2003;20:769-76.

12. Balinska-Miskiewicz W, Boznanski A, Liebhart J, Malolepszy J, Grabowski M, et al. Description of adverse drug reactions in multispeciality hospital and monitoring pharmacovigilance. Adv Clin Exp Med. 2006;15:81-3.

13. Mujahid M, Sharma M, Aqil M, Iqbal D, Kapur P. Drug utilization and adverse drug reaction monitoring in NSAID users in South Delhi. Int $\mathbf{J}$ of Res in Pharmacy and Chemistry. 2012;2(1):103-8.

14. Dhikav V, Singh S, Anand KS. Newer nonsteroidal anti-inflammatory drugs: A review of their therapeutic potential and adverse drug reactions. J IND Acad Commun Med. 2002;3:332-8.

15. Boelsterli UA. Diclofenac induced liver injury: A paradigm of idiosyncratic drug toxicity. Toxicol Appl Pharmacol. 2003;192:307-22.

16. Sulleyman H, Cardirci E, Albayrak A, Hallici Z. Nimesulide is a selective COX-2 inhibitory, atypical non-steroidal anti-inflammatory drug. Curr Med Chem. 2008;15:278-83.

17. Sriram S, Ghasemi A, Ramasamy R, Devi M, Balasubramanian R. Prevalance of ADRs at private tertiary care hospital in South India. J Res Med Sci. 2011;16(1):16-25.

Cite this article as: Dey S, Kumar H, Shukla AK. Safety reporting study of nonsteroidal antiinflammatory drugs in a tertiary care teaching hospital, SIMS, Uttar Pradesh. Int J Basic Clin Pharmacol 2020;9:1544-8. 